\title{
Poder y Sacralización del Paisaje en los Andes Centrales: Una aproximación
}

\section{Power and Sacralization of the Landscape in the Central Andes: An approach}

DOI: $10.46814 / \operatorname{lajdv} 3 n 5-053$

Recebimento dos originais: 01/09/2021

Aceitação para publicação: 26/10/2021

\section{Carlos Farfán Lobaton}

Laboratorio de Arqueología y Antropología Física y Forense de la Facultad de Humanidades Universidad Nacional Federico Villarreal, Lima - Perú

E-mail: carlosf21@ @otmail.com

\section{Victoria Aranguren Canales}

Facultad de Humanidades de la Universidad nacional Federico Villarreal.

E-mail: tolita@outlook.com.pe

\section{RESUMEN}

Este articulo está basado en estudios realizados en los andes centrales, principalmente lo que corresponde a los departamentos de Lima, Ancash y Junín, logrando identificar asentamientos prehispánicos en estrecha relación a los asentamientos actuales, articulados a una geografía sagrada claramente identificada por la gran mayoría de las comunidades actuales. Esta sacralidad del paisaje obviamente se remonta a la época prehispánica y en muchos de los casos tienen su continuidad en la memoria de las comunidades actuales donde se guarda la esencia fundamental de su origen. Para entender esta sacralidad y la sacralización, identificamos los indicadores conceptuales que sostienen lo sagrado en el pensamiento del hombre tomado en cuenta los conceptos ontológicos de lo sagrado y lo profano y su relación con el paisaje socializado. Cuando lo sagrado y lo simbólico es manipulado por los grupos de poder, entonces la sacralidad y la sacralización también son asumidas como mecanismos de control, no solo de lo ideológico, sino también la apropiación territorial, control de los sistemas de producción, de la acumulación de riqueza basada en ofrendas y tributos. Por ello nuestro propósito es de alguna manera aproximarnos a identificar y aislar algunos de los rasgos y factores causales del proceso de sacralización del paisaje tomando en cuenta el segmento de tiempo transcurrido desde su origen.

Palabras claves: Sacralización, paisaje, simbólico, poder, ofrendas.

\section{ABSTRACT}

This article is based on studies carried out in the central Andes, mainly in the departments of Lima, Ancash and Junín, identifying pre-Hispanic settlements in close relation to the current settlements, articulated to a sacred geography clearly identified by the great majority of the current communities. This sacredness of the landscape obviously dates back to pre-Hispanic times and in many cases has its continuity in the memory of the current communities where the fundamental essence of its origin is kept. To understand this sacredness and sacralization, we identify the conceptual indicators that sustain the sacred in human thought, taking into account the ontological concepts of the sacred and the profane and their relationship with the socialized landscape. When the sacred and the symbolic are manipulated by power groups, then sacredness and sacralization are also assumed as mechanisms of control, not only of the ideological, but also of territorial appropriation, control of production systems, of the accumulation of wealth based on offerings and tributes. Therefore, our purpose is to identify and isolate 
some of the features and causal factors of the process of sacralization of the landscape, taking into account the segment of time elapsed since its origin.

Keywords: Sacralization, landscape, symbolic, power, offerings.

\section{INTRODUCCIÓN}

El termino paisaje, sacralización y poder son conceptos que en los últimos años se ha ido afianzando en el discurso teórico de las investigaciones arqueológicas. Para entender con mayor claridad estos conceptos sería conveniente, en primer lugar, esbozar de manera muy apretada los antecedentes teóricos de la arqueología desde la década de los 70’ del siglo pasado que nos permitirá comprender el largo camino que ha recorrido la visión teórica de la arqueología peruana.

Recuerdo cuando aún era estudiante en la UNMSM, la teoría arqueológica estaba cargada del enfoque sistémico y ecologista dentro del modelo hipotético-deductivo hempeliano. Gándara a su tiempo recuso estas posturas haciendo sendos análisis de la historia de la arqueología bajo la denominación "La Vieja Nueva Arqueología” a inicios de la década de los 80” (Gándara, 1980). Paralelamente, también se imponía el estructuralismo casi como un paradigma dentro de la antropología bajo los principios esbozados por Levi-Strauss (1968, 1969 y 1970 primera, segunda y tercera edición) seguido de sendos estudios de la obra de Levi-Strauss que más adelante se darían intentos de aplicar la corriente marxista al estructuralismo que pretendía conciliar el método dialectico con el método estructural (Roger Garaudy, 1966 y Lucien Seve, 1974). A partir de estos enfoques se hicieron intentos por explicar los fenómenos sociales, tanto desde la antropología como de la arqueología.

Sin embargo, en nuestro medio, había copado en todos los ámbitos de la investigación arqueológica, esta nueva postura con enfoques basados en el énfasis del medio ambiente o ecologista donde aparecen las figuras más sobresalientes como la de Kent Flannery (1967), L. Binford, (1972), D. Clark, (1968, 1978, 1984: primera, segunda y tercera ed.) y Patty Jo Watson, Leblanc, Redman, (1974, 1981: primera y segunda ed.), solo por citar algunos, básicamente con la incorporación de la teoría de sistemas y el modelo hipotético deductivo que a la postre se le conoció como la Nueva Arqueología, que se convirtió en una tendencia casi paradigmática, que recusaba la arqueología histórico-cultural y el evolucionismo. En ambos enfoques, las preocupaciones estaban centradas en el examen cada vez más exhaustivo de la cultura material y su relación con el medio ambiente. Consecuentemente, en la nueva arqueología, el estudio de la cultura material desembocaba en una vertiente donde el dato empírico era organizado para convertirlos en datos cuantitativos y taxonómicos, por lo que la sistematización y formalización de la información era el objetivo más frecuente. De 
manera que, a partir de los problemas concernientes a la cultura material, se analizaba e interpretaba la actividad de las sociedades desaparecidas. Así, el medio ambiente ingresaba a formar parte de la estructura analítica de la arqueología, pero como sistema bajo el principio de adaptación. Pero sería Binford quien propone el análisis de la cultura material en su dinámica, explicando que es entender el artefacto en su funcionamiento y la estática es ver el artefacto tal como lo hallamos en las excavaciones, para ello sugiere las analogías etnográficas y el análisis inferencial basado en la teoría de alcance medio (Binford, 1972, 1988). Este enfoque debía conducir a las teorías generalizadoras acerca de la dinámica del pasado (Johnson, 2000) que influyo grandemente en las interpretaciones del cambio cultural. Entonces la arqueología había desarrollado una suerte de sistematización del dato empírico, este hecho tenía una percepción positivista de la realidad en su versión del positivismo lógico, (Johnson, 2000), apegado al cientificismo y a una tendencia de formalización de los fenómenos sociales y que se sostenía sobre la base de la filosofía de la ciencia cuyos exponentes más conspicuos fueron Karl Hempel (1979), Karl Popper, (1972) y Thomas Kuhn (1971). Los cuestionamientos a estas posturas no se dejaron esperar y surgen a partir de la necesidad de explicar el fenómeno del cambio cultural atribuyendo a factores causales en la conducta del hombre ligados al pensamiento simbólico consustancial al ser humano, que precede al lenguaje y a la razón discursiva, (Eliade, 1979:12), por lo que su dimensión de análisis no solo involucra al producto material del objeto sino también al hombre, lo que significaba “...que la cultura material, toda ella, tiene una dimensión simbólica tal que afecta a la relación entre comunidad humana y las cosas..." (Hodder, 1994). Del mismo modo, M. Johnson (2000), diría que "la interpretación arqueológica es siempre hermenéutica”, es decir, busca la interpretación de los significados de la cultura material. Así, quedaba claro que solo la cultura material como objeto no era suficiente para explicar la conducta del hombre, sino había que recurrir a otros indicadores no materiales detrás de los materiales. Esta etapa coincide con la el apogeo de la posmodernidad que trajo como consecuencia el advenimiento de la arqueología pos-procesual que concentra su objetivo en la discusión de las dicotomías objeto y sujeto (Bate, 1998), entre la organización del espacio construido vs espacio social, donde para el primero, se enfatiza el manejo del territorio y el medio ambiente, y para el segundo, se prioriza la población como actores sociales dentro de una dinámica que involucra el espacio simbólico. Sin embargo, dentro de un análisis más holístico, encontramos la dicotomía Espacio y Poder vs. Espacio Sagrado. En el primero, se involucra las unidades de producción, unidades de consumo, unidades de almacenamiento y manejo del espacio que en el fondo son los indicadores de una estructura simbólica del poder. En tanto que los Espacios Sagrados enfatizan dos variables, una referida a los espacios construidos con fines sagrados, como los templos, adoratorios, ushnus, etc. y aquellos que se convierten en Espacios Sagrados a través del rito y del mito en un tiempo sagrado, como son las plazas, los caminos, las acequias, las apachetas, los 
cementerios, las lagunas, puquios, etc. Estas dicotomías son perceptibles en la organización del espacio social, pero que están articulados al entorno como un paisaje integrado que guarda un "equilibrio" simbólico en la sociedad. Este entorno es el llamado paisaje natural y la conforma la configuración territorial, identificados y socializados por el hombre a través primero, de la apropiación y luego de la sacralización producto de una larga experimentación en su vida cotidiana. Estos paisajes están referidos a las montañas más altas, cuevas, puquios, lagos y lagunas, ríos, nevados, el mar, etc., y configuran el pensamiento del hombre, por lo que en la materialización del espacio construido se percibe el paisaje social integrado.

Entonces, ¿cómo y porque se sacraliza el paisaje?, ¿Cuántos tipos de paisaje sacralizado se conocen para los andes centrales?, ¿Cuál es el origen de lo sagrado en el mundo andino?, ¿los conceptos de Paraidolia y las Hierofanias forman parte de la sacralización del paisaje? Son cuestionamientos que pretendemos aproximarnos y abordar basado principalmente en datos de campo reunidos a lo largo de los últimos 25 años en los andes centrales, de manera que tanto la fundación de los asentamientos, el origen étnico, de linaje, la circulación del agua, los ciclos agrarios, la fecundación, la vida y la muerte, el territorio y poder, todos ellos estaban ligados estrechamente a fenómenos sacralizados que legitimaban un orden social y equilibrio consustancial al medio ambiente.

\section{PAISAJE Y SACRALIZACIÓN}

Los datos de campo que disponemos fueron obtenidos de toda el área que comprende el departamento de Lima y el sur de Ancash, principalmente las áreas de sierra donde hemos identificado asentamientos prehispánicos y asentamientos actuales, articulados a una geografía sagrada claramente identificada por la gran mayoría de las comunidades campesinas (Fig.1). 
Fig. 1

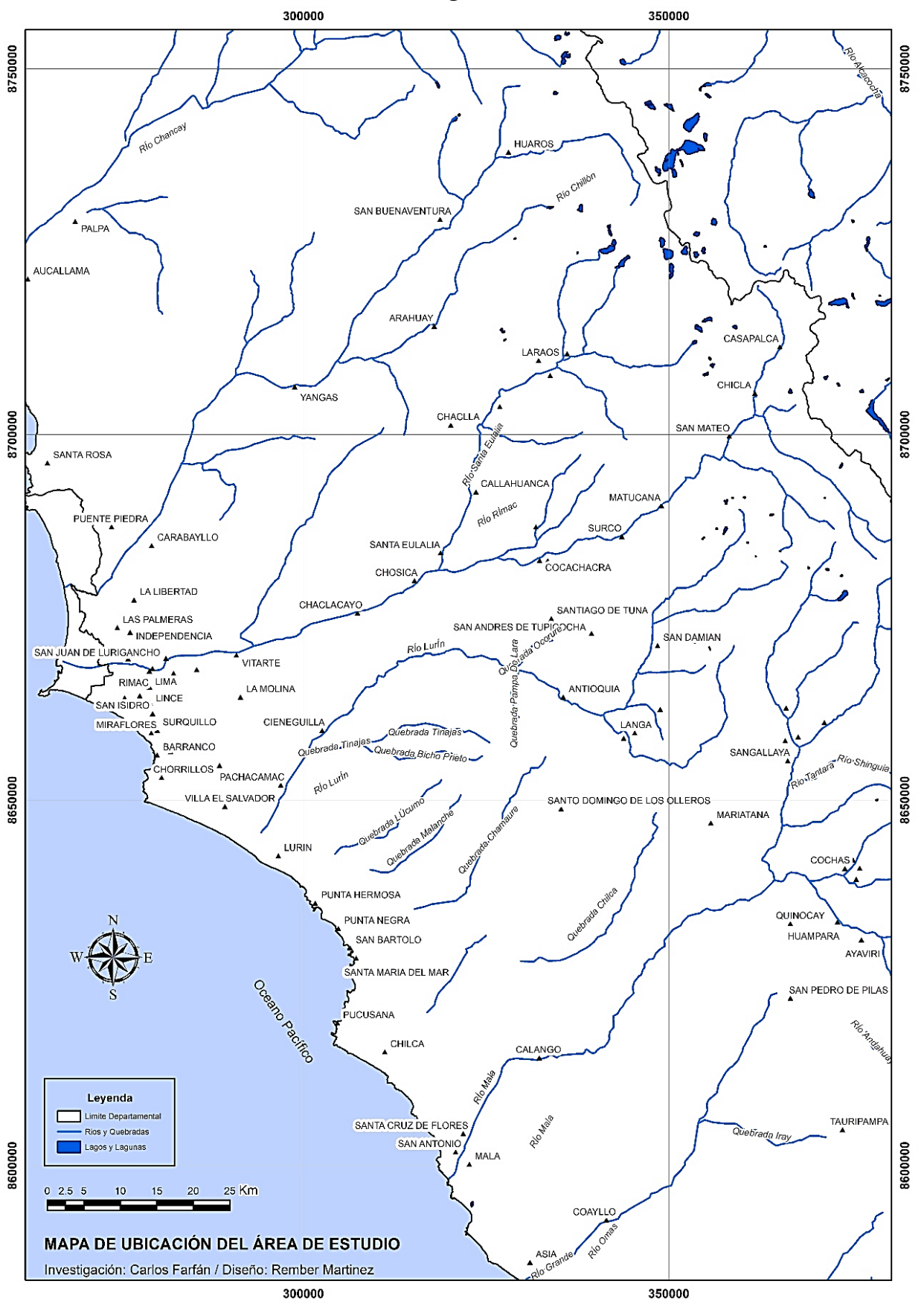

Para entender esta sacralidad y la sacralización debemos tener en claro los indicadores conceptuales que sostienen lo sagrado en el pensamiento del hombre. Muchos autores han tocado estos puntos, pero no tanto como M. Eliade $(1973 ;$ 1979) que nos aclara la versión ontológica de este concepto donde lo sagrado y lo profano es una dicotomía de oposiciones, así, “...la primera definición de lo sagrado es la que se opone a lo profano”, (Eliade, 1973:4). Entonces, ¿en qué momento se percibe lo sagrado? Cuando ingresamos a la dimensión fenomenológica del hombre, percibimos que hay una realidad que se percibe y otra la que se concibe en el consiente, así tenemos las personas que ven en el paisaje formas de animales, de personas, escenas ligadas a su vida cotidiana, a este fenómeno 


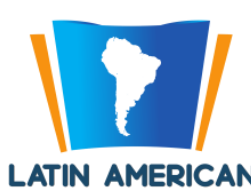

LATIN AMERICAN

se le denomina paraidolia y cuando estas figuras o formas se "...manifiesta en la mente y comienza a buscar explicaciones para este parecido y establece relaciones con eventos que no guardan relación directa, pero comienzan a dar forma a una historia coherente, se le denomina Apofenia" (Bustamante, 2008). Tanto la paraidolia como la apofenia conducen a sacralizar estas imágenes y por extensión el paisaje, por lo que se le denomina también hierofania.

Estos fenómenos de percepción de la realidad la hemos registrado en nuestros estudios de los valles de Chillón y Huarochirí. Hemos conversado largamente con pobladores de las comunidades campesinas que aun practican rituales de "pago" a la tierra, hablan de la vía láctea (hatun mayu), del ciclo agrario ligado al ciclo de sus festividades ancestrales, tales como fiesta del agua que es la más arraigada y con una carga simbólica muy rica. En la comunidad de Huaros del valle alto del Chillón, se conoce la llamada piedra pescado, ubicada en las faldas de la pendiente de Ranrachani; la bandera del Perú, ubicada al frente de Huaros en las faldas del Cerro Colorado; la imagen de Churcuña y la diosa del ganado, ubicadas en las mesetas de Yanauya (Fig. 2 y 3). En Lachaqui del mismo valle, se identifica la piedra llama, ubicada en el cerro Pallpay cerca de Lachaqui; el toro barroso, ubicado en una formación rocosa camino a la toma de agua del canal de Yaurimama, y la imagen de la virgen, en la misma ruta. Todas estas formas no son otra cosa que la continuación de la tradición ancestral de ver en el paisaje arquetipos de la sacralidad de las formas relacionadas con el mundo de sus dioses y su cosmovisión. Se puede decir que estos fenómenos de percepción de la realidad organizan la conducta y configuran una estructura simbólica capaz de visualizar racionalmente el espacio, consecuentemente la materialización de esta conducta está presente en todas las manifestaciones culturales.

Fig.2: Churcuña deidad del ganado

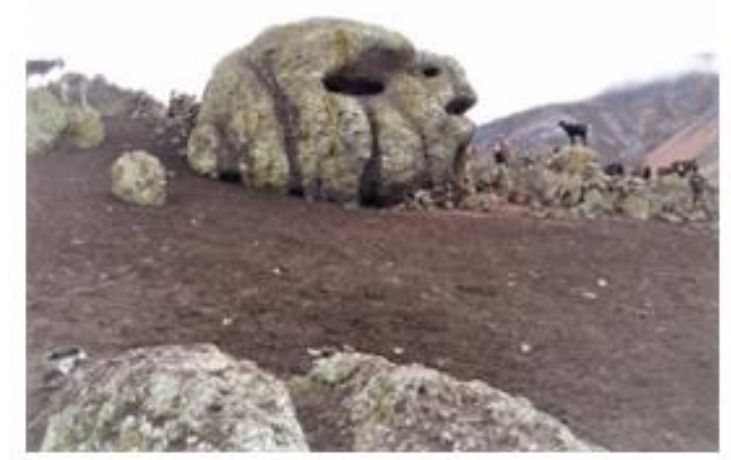

Fig.3: Churcuña la diosa del agua

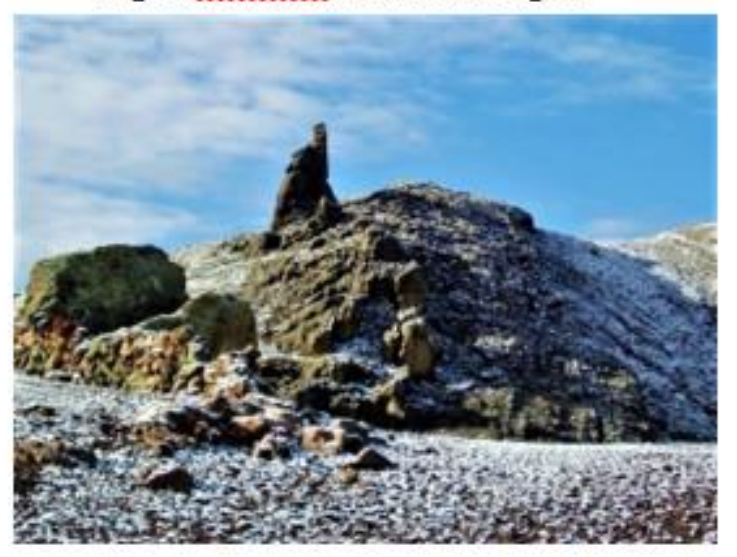

La configuración arquitectónica de un asentamiento, la elección del hábitat y emplazamiento, necesariamente tienen referentes simbólicos sacralizados porque las comunidades prehispánicas que eligieron un espacio para su hábitat no han visto solamente los recursos disponibles, ni las mejores tierras para el cultivo, sus referentes estaban en el paisaje como "mensajes sagrados", donde solo había 


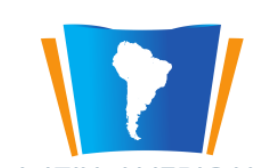

LATIN AMERICAN

que diferenciarlos y asociar a su mundo simbólico, es así como identificaron un puquio, una roca un cerro o un nevado, quizá una laguna como su pacarina o lugar de origen o rutas de dioses y guerreros, de manera que para legitimar este origen se construyeron mitos, historias y rituales evocativos, que por lo general, se volvieron cíclicos. Un ejemplo está referido a la circulación del agua en la comunidad de Huaros, (Fig. 4).

Fig. 4

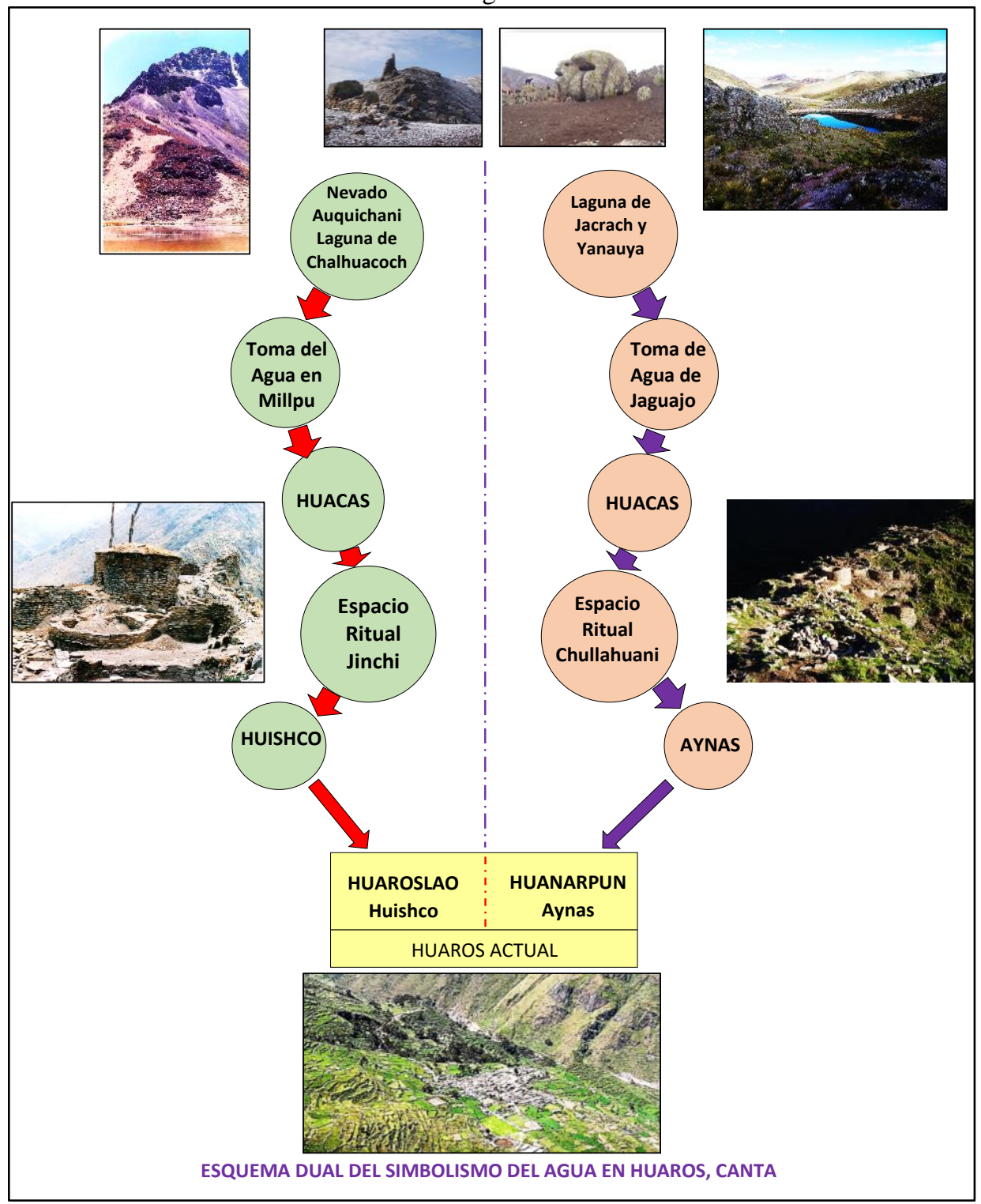


Esta comunidad tiene dos canales ancestrales, una llamada canal de Millpo, otra canal de Jaguajo. El primero es captado del rio Yamecoto que nace de la laguna de Chalhuacocha cerca del nevado de Auquichani y pasa por un espacio ritual denominado Mirpo donde existe una huaca que es una cueva entre las rocas y el asentamiento arqueológico de Huishco (Fig. 5). Este canal irriga las partes altas de Huaros.

Fig. 5

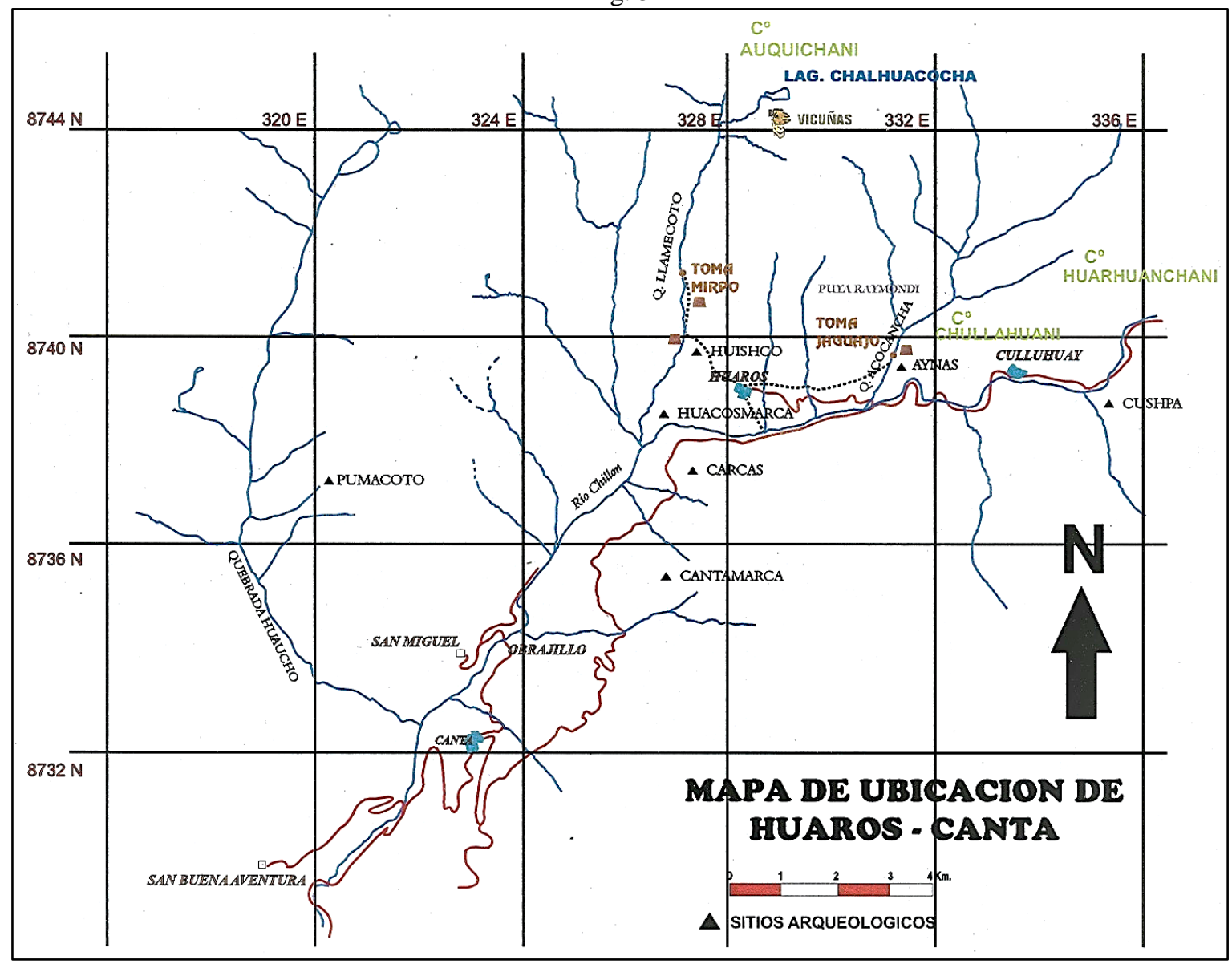

El canal de Jaguajo o canal de Runtu nace en las lagunas Jacrash y Yanauya pasa por la toma de Jaguajo donde se conoce la existencia de dos huacas materializadas en piedras denominadas huancas (hombre y mujer) y luego de un espacio ritual llamado Chullahuani y muy cerca se halla el asentamiento prehispánico de Aynas. Como podemos apreciar hay una estructura de sacralidad articulada a los asentamientos ancestrales y huacas que para las comunidades que venimos estudiando son los llamados huancas las dueñas del agua. Claramente vemos la sacralización del paisaje en torno al agua donde también aparecen otros actores que protagonizan los rituales: los parianes (en este caso serían los chacrayoc, los que velan por el agua), los quivios (francolina), aves relacionadas a la venida 
del agua. En su apareamiento danzan en las nieves (danza de los quivios) $)^{1}$, las huancas ${ }^{2}$ que son ancestros litificados y están en la toma del agua (Fig. 6), el zorro que es la transformación del parian a su paso por el canal cuando se ha limpiado y purificado el agua, los nevados y lagunas que son los orígenes del agua ${ }^{3}$, (Ver también la Fig.4).

Fig.7: Mama Capiama dueña del agua en Llambilla, Huarochiri relacionada al adoratorio del nevado de Pariacaca

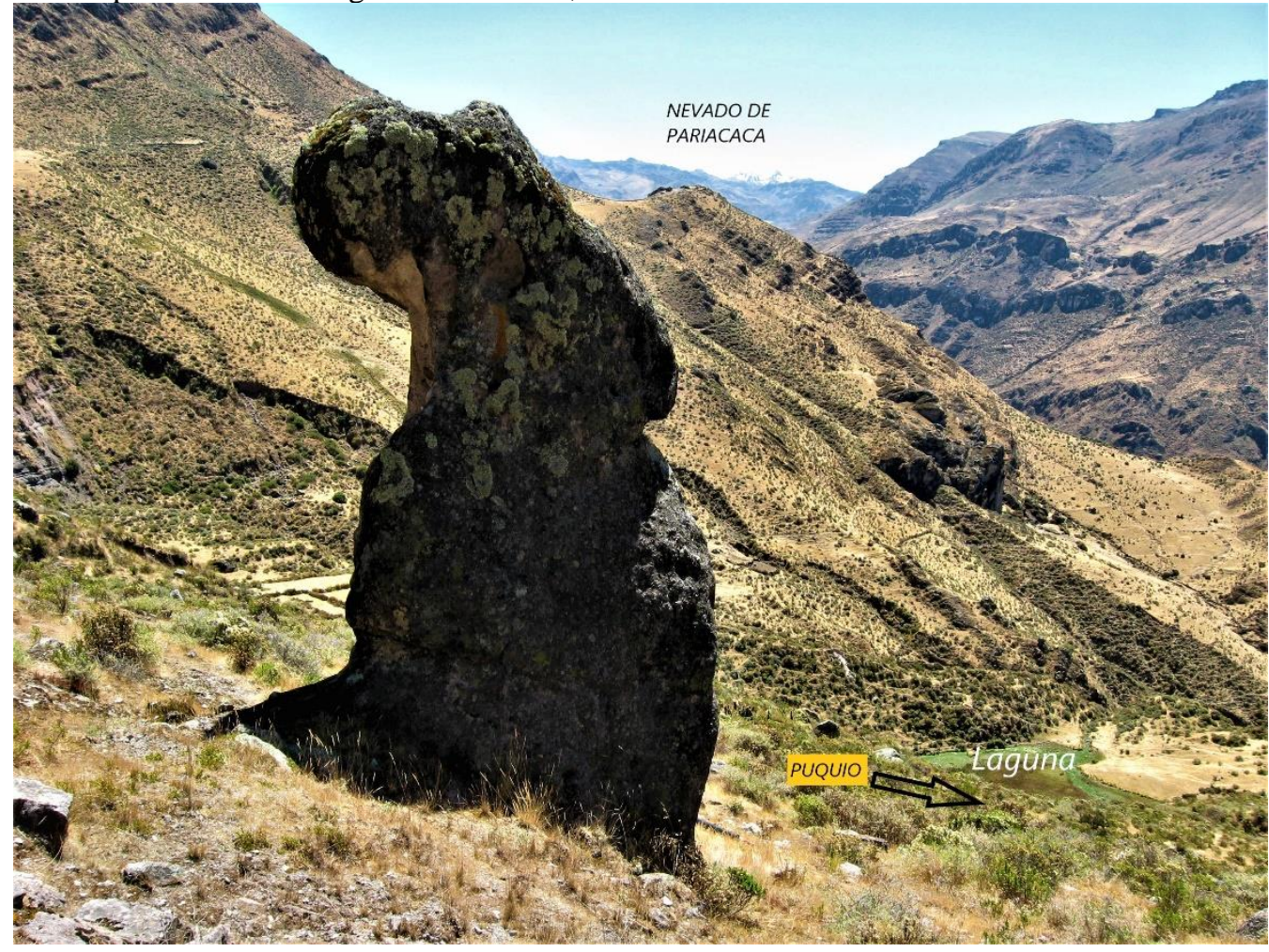

En estas fechas la comunidad entra a un tiempo donde todo ritual y acto está sacralizado, desde las hierbas de huamanripa y flores que se utilizan en los actos rituales de los comuneros, hasta la chicha negra y chicha blanca, por lo que son conservados y colocados junto a las semillas que están destinados para la siembra, (Fig. 7). En Lachaqui existe un mito de origen donde se cuenta que de la laguna de Lorococha vinieron los primeros pobladores de Lachaqui; en Culluhuay se cuenta otro mito similar donde señalan que los antiguos pobladores de Culluhuay bajaron de las alturas del cerro Ñaupajayan vestidos con cueros de camélidos y en estado muy salvaje y vivieron en huecos hecho en los árboles cuando todo era bosque (Farfan, 2002)

\footnotetext{
${ }^{1}$ Durante la fiesta del agua en Huaros se ejecuta la Danza de los Quivios. Los quivios son hembra y macho. Son jóvenes varones disfrazados. El macho se vestía con jergas cubiertas todo el cuerpo, el sombrero enflorado con paja, el macho lleva una jeringa para defender a su hembra, a su vez el macho trataba de "pisar" a la hembra y éstas hacían el ademan de sentarse. Bailaba pronunciado la palabra "quivio, quivio". Luego hacia su aparición el "caballero" en número de dos, cada uno con su perro galgo (era una persona disfrazada de perro) jalados por una cadena, estaban bien vestidos a la usanza española. Los perros adoraban la cruz y simultáneamente hacen su aparición los pollitos quivios y comienza una cacería. Los caballeros usando sus armas persiguen a los quivios ayudado por los perros quienes atacan. Los caballeros logran capturar a los quivios y los matan, seguidamente los llevan a una mesa donde son rociados con chicha negra simulando que es la sangre de los quivios, esta "sangre" es ofrecida al público como símbolo sagrado, (Santos Hurtado 2003).

${ }^{2}$ Piedras alargadas plantadas en la tierra y pueden estar en las tomas del agua, en medio de las chacras y en el pueblo prehispánico.

${ }^{3}$ Las fechas que se evocan los rituales propiciatorios del agua es el 30 de agosto para el canal de Jaguajo y el 21 de noviembre para el canal de Millpo.
} 


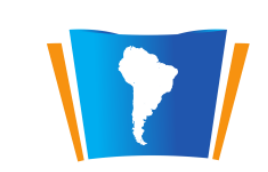

LATIN AMERICAN

Fig. 8: Ritual del agua y el sincretismo en el Canal de Mirpo, Huaros, Canta

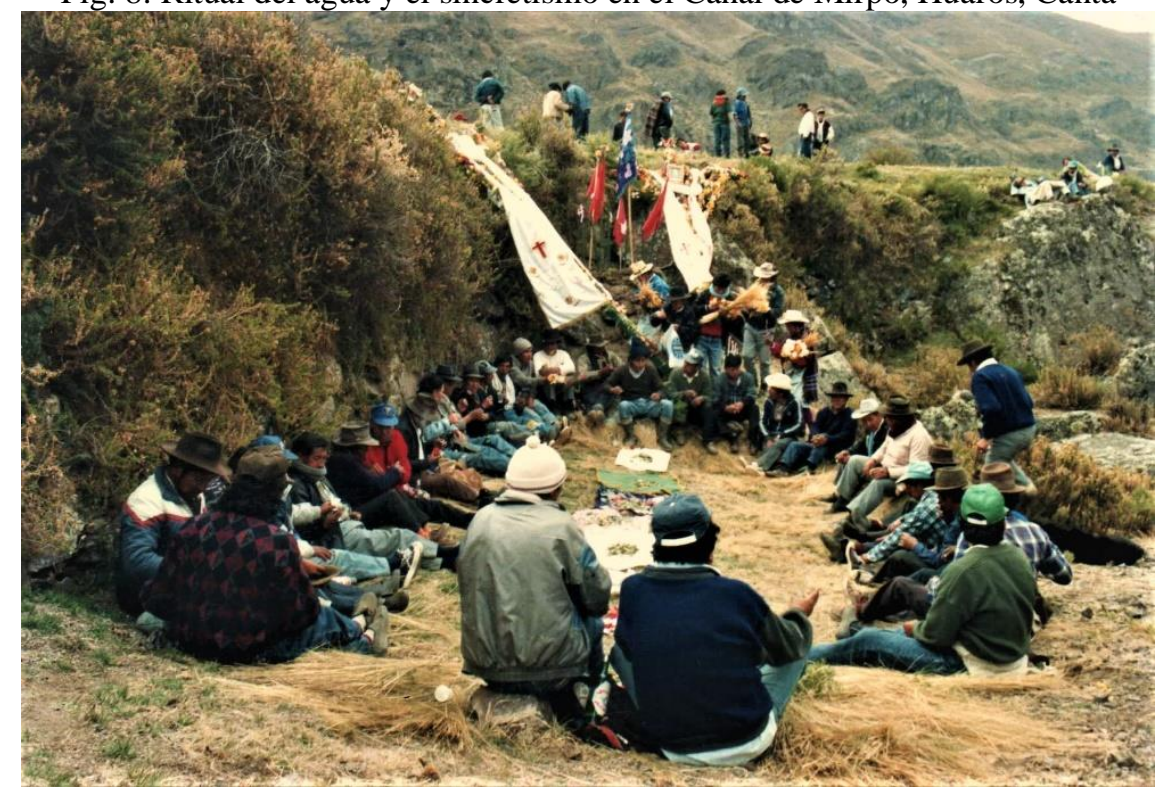

Hay también otros paisajes sacralizados en la cuenca del Chillón. En nuestros recorridos por la cabecera de la cuenca alta cercana a la cordillera de la Viuda se narra un mito:

El “Wakon, era un dios maléfico que vivía -según el mito-, en una caverna o cueva denominada Wakonpahuain al pie del cerro Reponge; por su presencia ardía una hoguera. Allí vivía un hombre semidesnudo llamado Wa-Kon. Su atributo principal era comer gente" (Villar Córdova, 1938).

El mismo relato se cuenta en Huaros, dicen que el citado Wa-kon (wajun en Huaros) radica en una cueva denominada Shotoccacca, muy cerca del lugar en el paraje denominado Waypian, (Foto 8). En la actualidad, ahí existe un farallón donde la gente teme pasar cuando esta con mucha neblina y de noche. En suma, este personaje según los relatos y documentación escrita habitó las escarpadas cuevas de la cuenca alta entre Huaros y Culluhuay. Otro lugar sagrado, es Quipachaca (puente de las cargas), se trata de un puente natural sobre el rio Chillón sobre el camino prehispánico. Está conformado por rocas naturales donde el agua de rio pasa por debajo. En este lugar el viajero o arriero que sube o baja por el camino deja una piedra pequeña en el lado de la margen izquierda: dicen que debe ser tantas piedras como cargas lleva o trae, es también porque cruza de una margen a otra. Según la creencia es que el viajero que sube está llevando sus productos para intercambio y para que se materialice el intercambio debe dejar tantas piedras como cargas lleve, así el maíz de abajo se transforma en cargas de carne, papas ocas que son los productos de arriba y viceversa los que bajan harán lo mismo para convertir sus cargas de carne, lana, ocas, papas en maíz, ají, frutas, etc. Este lugar de Quipachaca recuerda a las apachetas, pero su significado es muy distinto. Siguiendo rio abajo, existe otro paraje denominado "Puente Negro", se halla casi a $1 \mathrm{~km}$ más abajo de Quipachaca es un lugar donde se juntan 
el rio Yamecoto con el Chillón. En este lugar, dicen radica un personaje maléfico, nadie explica quién o qué es, pero es el paso más temido en este camino prehispánico de Huaros a Canta.

Fig. 8: la imagen del wajun en la cueva de Shutuccacca en las cercanías de Huaros

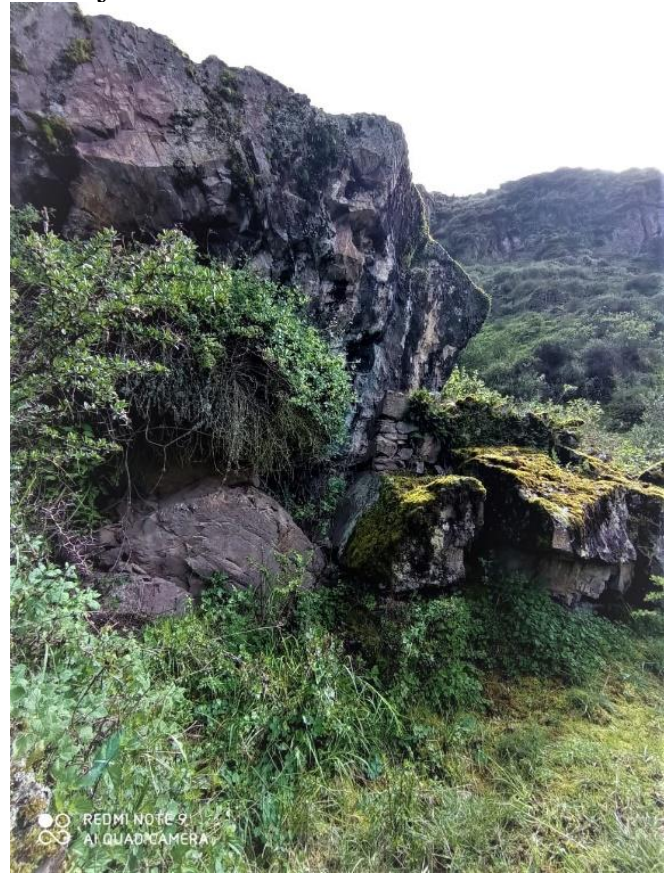

Fig. 9: Adoratorio de Cahuara en la cima del cerro Lucana, Lachaqui, Canta

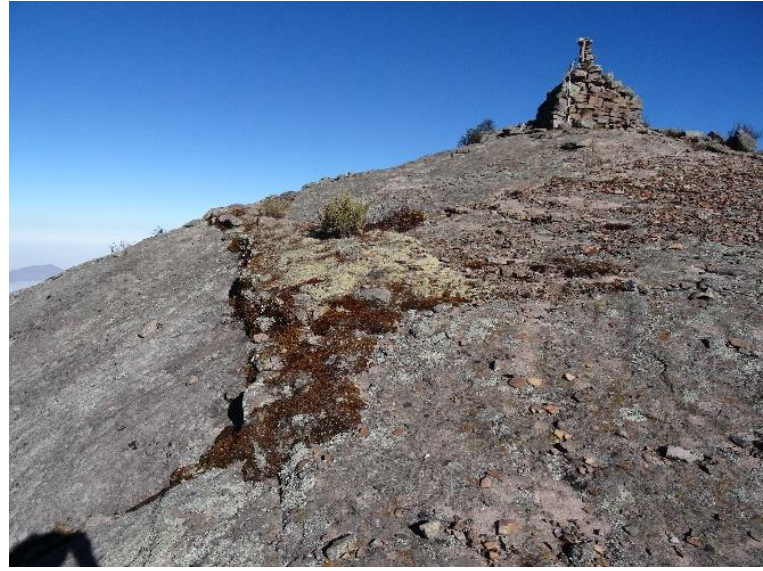

Luego, entre Carhua y Viscas, tenemos el cerro Cahuara a 4200m.s.n.m., (Fig.9) es el cerro más alto de esta área donde se practicó el ritual de la Capacocha y aun se sigue ofrendando a este cerro en rituales secretos por el pueblo de Viscas. En la cumbre de este cerro existen restos arqueológicos formando patios y recintos en torno a una plaza presidido por una formación rocosa donde se halla la cueva donde dicen que está enterrada una niña llamada María Pallachu.

\footnotetext{
${ }^{4}$ Es un trabajo presentado al Instituto de Investigación de la Facultad de Humanidades de la UNFV. Lleva el título de Cahuara: oráculo y Capacocha en la cuenca alta del Chillón. Proyecto de investigación 2014
} 


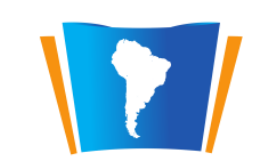

LATIN AMERICAN

En la parte media y baja del valle, casi no quedan huellas de estos espacios sacralizados, quizá sea debido a que esta franja es área de tránsito intenso, sin embargo, vale la pena mencionar que uno de los rasgos más conspicuos de esta zona media son la presencia de los petroglifos con alta concentración de simbologías que marcan rutas sagradas y territoriales y aparecen desde periodos muy tempranos, específicamente desde el Formativo u Horizonte Temprano (1200 a.C. a 200 a.C.). Estas evidencias fueron reportadas por Guffroy (1999) adjudicando una significación simbólica de poder asignada al cultivo de coca en esta área media del valle. Pero, no solo son los petroglifos de Checta al cual se refieren Guffroy, sino también hay otros petroglifos que nosotros ubicamos en la zona de Punchauca y Zapan, (Fig.10), que estarían marcando posiciones astronómicas y de linderación en el valle. En la zona baja cerca de las pirámides formativas de Huacoy y Chocas, se ubica el Cerro Con Con que según Rostworowski (1977) y Villar Córdova (1935), sería la misma pirámide de Huacoy y estaría referenciado al dios Kon, una deidad pan andina. Robert Benfer y Hugo Ludeña desde el 2004 vienen investigando en Buena Vista, un templo Pre-cerámico relacionado a la fase Mito de Kotosh, presencia de esculturas en barro y chicras (Benfer y Ludeña, 2004). Su significación dentro del paisaje sagrado temprano radica en que su construcción tiene orientaciones astronómicas. De manera, que se presume que desde periodos tempranos aparece sacralizado el paisaje. Este templo está asociado a personajes como el zorro en Buena Vista y el famoso dios Con asociado a grandes pirámides del periodo Formativo. No obstante, estas referencias, también están involucrados dentro de relatos míticos y narraciones orales asociadas a otras deidades locales que convierten al escenario de la cuenca en espacios sagrados.

Fig.10: Petroglifos de Zapan margen derecha del Rio Chillón, Canta

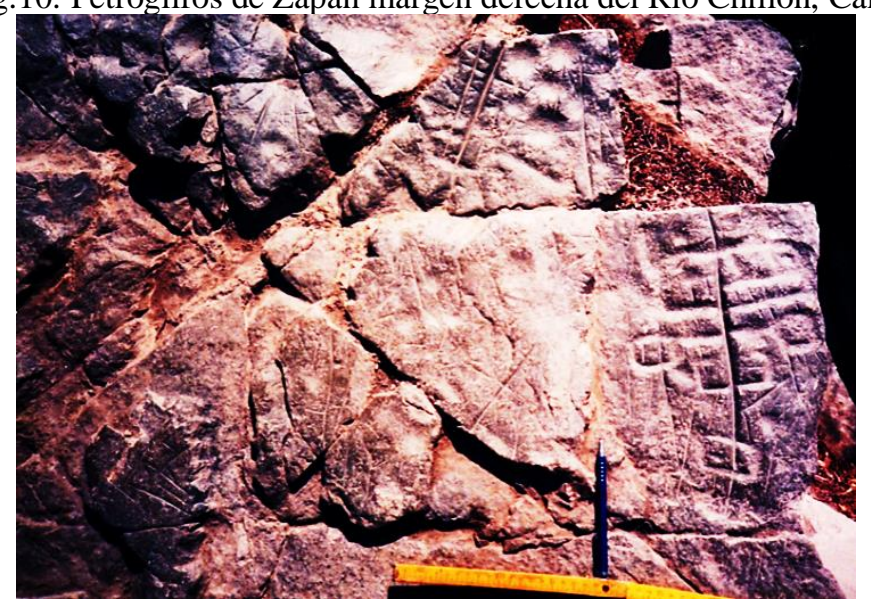


Fig. 11

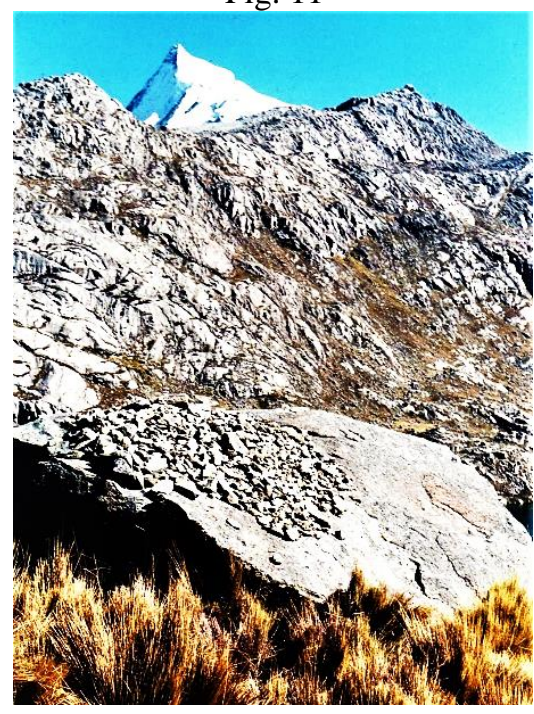

Otro de los aspectos trascendentales, fueron las redes viales que articulaban los dominios territoriales de los curacazgos y posteriormente por el estado inca conforme se incrementaban sus conquistas. Los incas le dieron un énfasis preferencial en su manejo y administración política. J. Murra proponía que los caminos jugaban un papel importante dentro de la política del Tawantinsuyo en el proceso de incorporación de las diversas etnias conquistadas por el estado inca, sistema que relacionaba la periferia con el centro y la costa con el altiplano (Murra, 2002). Por esta razón el Qapaqñan o Inkañan fue un complejo sistema administrativo, de transportes y de comunicaciones, así como un medio para delimitar las cuatro divisiones básicas del imperio (los cuatro suyos), (Hyslop, 1992). De tal manera, que los caminos debían estar dotados de una serie de equipamientos para cumplir estas funciones. Sin embargo, las redes viales, además de estar equipados por los tambos, también son visibles otros elementos quizá los más determinantes, nos estamos refiriendo a una serie de lugares sagrados o míticos tales, como apachetas, apus y wamanis, nevados, puquios, adoratorios, etc., (Fig.11) consideradas como símbolos sagrados ligados a mitos de origen de propiciación, orientaciones y otras significaciones sagradas que le daban al camino un valor sacro y a la vez político. De este modo, los caminos constituían un símbolo de poder omnipresente, del poder y autoridad del Estado Inka hacia los pueblos conquistados (Bauer, 1996).

Tanto el valle del Chillón como el valle de Lurín, Mala y Cañete estuvieron dotadas de redes viales que unían las partes bajas con las zonas altas. De todas ellas, las que más importancia y sacralidad presentan son Lurín y Mala que permite comunicar los grandes oráculos de Pachacamac y Pariacaca y delimitan una esfera de interacción sagrada. Es claro ver en estas relaciones dos dimensiones: una referida al conocimiento de un esquema simbólico cargado de ritualidad ligado a dos deidades tutelares, 
de la región yunga y de las cordilleras - Pachacamac y Pariacaca, respectivamente - y otra, referida al manejo económico y territorial como instrumento de dominación.

Estas evidencias que hemos mencionado sintetizan el carácter de sacralidad y poder en tanto se maneja el control económico y se manipula los fenómenos sagrados o sacralizados a través de la construcción de mitos y leyendas fabulosas que se materializan en el paisaje. Por ejemplo, la visión simbólica de Pariacaca y Pachacamac donde se estructura una dualidad (Fig. 12), ambos con significación divina que corresponden a dos espacios de oposición dentro de la mentalidad andina: Pariacaca como deidad serrana y Pachacamac como deidad yunga o de los llanos.

Fig. 12

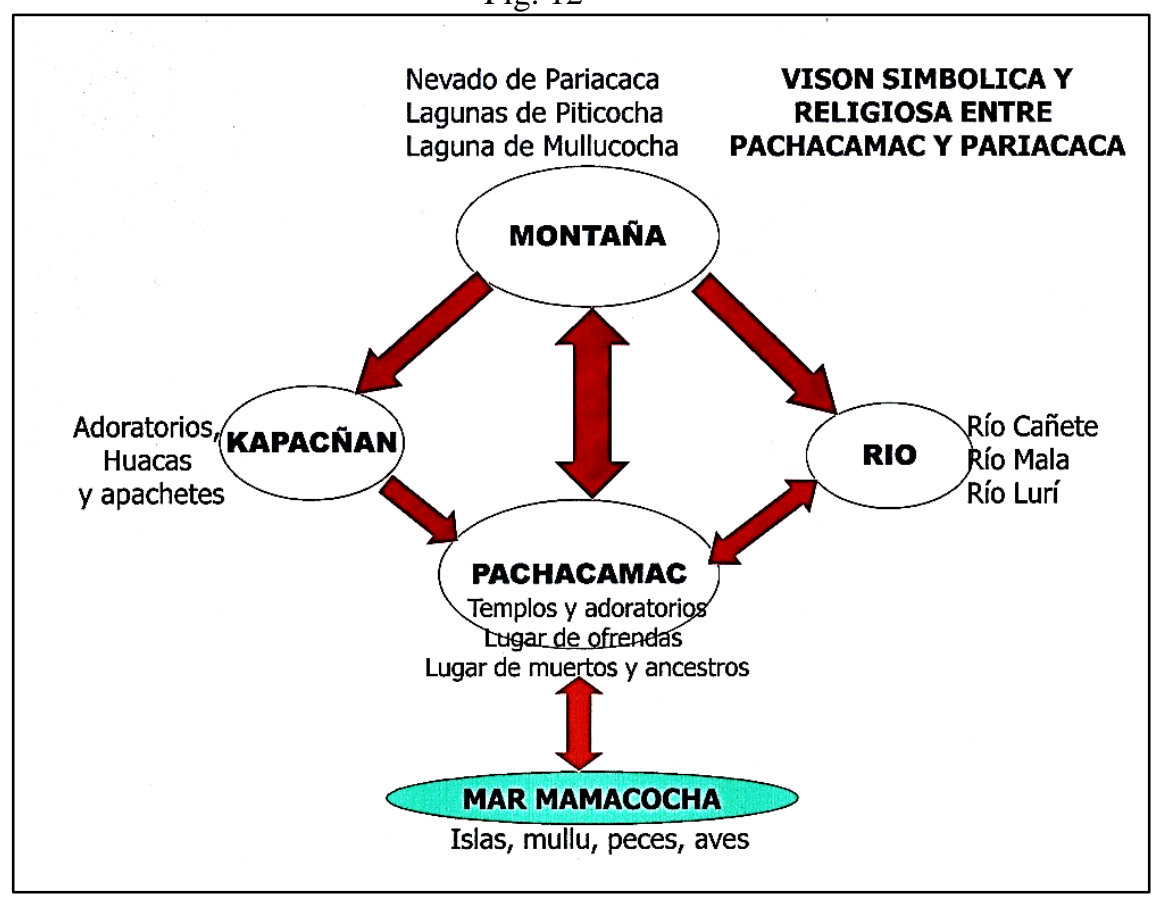

\section{ORDENAMIENTO TERRITORIAL Y SACRALIZACIÓN}

El ordenamiento territorial está relacionado al emplazamiento de los asentamientos y en cierto modo, al patrón de asentamiento. Los grupos humanos eligen un lugar para su hábitat y a la vez se apropian del paisaje circundante, en este caso, según el concepto del simbolismo del centro donde un pueblo:

\footnotetext{
“...al instalarse en un territorio, edificar una morada exige, una decisión vital, tanto para la comunidad entera como para el individuo. Pues se trata de asumir la creación del «mundo» que se ha escogido para habitar. Es preciso, pues, imitar la obra de los dioses, la cosmogonía...”. (Eliade, 1973).
}

En cierto modo, podemos entender de este modo, la sacralización parte desde la fundación del asentamiento, esto conlleva a sustentar y legitimar la apropiación del paisaje con todas sus 
características a través de historias y mitos estructurados como reflejo del paisaje circundante. Estos ordenamientos obedecen, de un lado, al espacio geométrico y a la vez al espacio simbólico imbricado en una cosmovisión racional. Así tenemos, a los incas que han sintetizado y sistematizado el ordenamiento territorial a través de varios conceptos (Zuidema, 1964; Urbano, 1988): el primero es la bipartición horizontal del espacio en Anan y Urin ${ }^{5}$, el segundo, es la tripartición en ichoc, allauca y chaupi, el tercero, collana, pallan y callao, el cuarto es la cuatripartición en los cuatro suyos Chinchaysuyo, Collasuyo, Antisuyo y Contisuyo (Zuidema \& Poole, 1982), finalmente tenemos la tripartición vertical Kay Pacha, Uku Pacha Anan Pacha.

En el caso de la cuatripartición establecida por los incas no es un caso aislado ya M. Eliade advierte esta partición para explicar el simbolismo del centro en otras sociedades:

\begin{abstract}
La división del pueblo en cuatro sectores, que implica por lo demás una partición paralela de la comunidad, corresponde a la división del Universo en cuatro horizontes. En medio del pueblo se deja con frecuencia un espacio vacío: allí se elevará más tarde la casa cultual, cuyo techo representa simbólicamente el Cielo (a veces indicado por la cima de un árbol o por la imagen de una montaña), (Eliade, 1973:13)
\end{abstract}

De manera que la cuatripartición en el estado inca implicaba dominio territorial sin límites, porque no se sabe dónde terminaba la línea imaginaria de los suyos, por lo que se presume que son límites de valor simbólico a la vez político y étnico, sea como fuera, obedece al mismo principio del simbolismo del centro, en este caso, con el centro en el Coricancha del Cusco, cuya discusión más resaltante entre Zuidema y Espinoza en cuanto a los límites de los suyos, (Ver también Espinoza, 1977 y Zuidema \& Poole, 1982). En relación a la tripartición de ichoc (izquierda), chaupin (centro) y allauca (derecha) se toma en cuenta al hombre como centro. También se debe considerar este concepto tomando en cuenta un orden lineal, desde el punto de un observador, es decir, dependerá desde donde lo vea para saber si es izquierda o derecha. No sucede lo mismo con la tripartición de collana, pallan y callao.

En este caso, estos nombres forman parte de la organización de los seques. Zuidema nos dice: “...el sistema de seques explica también la importancia del calendario para la organización social y la vida ceremonial” (Zuidema, 1995). También señala, “Los seques de un grupo de tres tenían respectivamente los nombres de collana, payan y cayao” (Zuidema. 1995:3). Zuidema ha estructurado una explicación del calendario a partir de los seques que a la vez organizaba a la sociedad cusqueña en panacas. También señala la clasificación binaria y tríadica dentro de un contexto social y jerárquico

\footnotetext{
${ }^{5}$ Para Enrique Urbano señala a manera de critica que Resulta, pues, en nuestros días, ridículo, absurdo y desproporcionado reducir todo el espacio simbólico andino a obsesivas "dualidades o cuatriparticiones" como lo hace Rostworowski en su libro de 1983, Estructuras Andinas del Poder (Urbano, 1987:213)
} 
(Zuidema, 1995). Pero no vamos a tocar por ahora este tema calendárico, pero si vamos a enfatizar como estas particiones articulan la organización del paisaje sagrado y la sociedad. Estos niveles de organización solo son posible cuando se tiene muy claro cómo funciona el ciclo vital y como está organizado el mapa celeste. Tal como señala Urton:

\footnotetext{
“...el sistema de seques funcionaba coincidentemente como mecanismo para organizar el calendario. De este modo, el sistema de seques combinaba el ordenamiento de espacio con el ordenamiento del tiempo", (Urton, 2006).
}

Definitivamente según la lectura de la organización y estructura del espacio en Misminay, Cusco, estudiado por Urton (2006), es una muestra más de la racionalidad y conocimiento del espacio cósmico articulado al espacio terrestre y la sociedad y que se debió plasmar en todos los dominios del estado inca, solo que falta identificarlas y aislar los indicadores simbólicos que ordenan el paisaje.

En relación al principio de organización dual, debemos decir que su carácter es más complicado, no solo es una bipartición del espacio, es mucho más que este aspecto físico. Implica organización social, de manera que los conceptos de anan y urin, son consagraciones de un organismo donde prima la oposición y la complementaridad, en la sociedad, a la par que ocupan espacios en oposición también, en las sociedades de cada parte aparece oposiciones. Nosotros en un artículo publicado acerca de la bipartición del espacio y las plazas sagradas en la cuenca alta del Chillón (Farfan, 2002) dábamos a conocer la presencia de un sistema de plazas construidas ex profesamente durante la conquista inca en los extramuros de los asentamientos conquistados, así mismo, dichas plazas estaban dotadas de una huanca al centro, lo cual nos permitió interpretar que se trataba de un calendario solar, así mismo, dimos a conocer la presencia de un fenómeno bipartito de los asentamientos tanto prehispánicos y continuados luego durante las reducciones toledanas (Farfan, 2002), pero que no necesariamente tienen implicancias de una versión de dualidad. Estas evidencias en nuestra investigación toman relevancia, toda vez que tanto las plazas como la bipartición es una expresión del simbolismo consagrado por los incas en cada pueblo conquistado.

La bipartición del espacio se puede dar a nivel de macro áreas como las de Anan Yauyos y Urin Yauyos, cada cual formando grandes territorios generalmente limitado por los ríos o quebradas. Guamán Poma enumera a los grupos étnicos o provincias con sus respectivas mitades, entre otros dice:

\footnotetext{
“...yachas y yaros, anan y lurin Chaclla, anan y lurin Picoy, anan y lurin Canta, anan y lurin Upa Yauyo, anan y lurin Llacuaz Yauyo, anan y lurin Huarochiri Yauyo, anan y lurin..." (Guamán Poma, 1936: 1073)
}

Como podemos ver este concepto de bipartición es un hecho generalizado en el área andina donde es posible recrear todos los niveles del espacio, desde territorios conformados por ayllus y 
parcialidades hasta los barrios en un poblado. Pero este ordenamiento no es casual ni estaba basado en lo puramente económico o social, tiene sus soportes en un simbolismo y sacralidad y por ello la materialización de estos conceptos está en los asentamientos, en sus sistemas de enterramiento. Habría que rescatar o analizar más profundamente si en estas biparticiones tienen una esencia dual tal como señala Guamán Poma donde nos muestra una función la complementaridad y la oposición, los parentescos y las relaciones sociales más cercanas. Liliana Regalado nos aclara en relación a estas particiones y propone que se debe:

\footnotetext{
“...enfatizar que la dualidad y la tripartición constituyeron, en general, en la época prehispánica y de manera bastante visible durante el predominio incaico, criterios básicos de clasificación referidos entre otras cosas a la configuración del espacio sagrado, sustento de la organización social”, (Regalado, 1996:91).
}

Entonces la configuración del espacio sagrado esta sostenido en estas particiones que en su conjunto también expresa jerarquía y poder que fue uno de los “...objetivos de la manipulación de los conceptos y rituales religiosos tradicionales...", (Conrad y Demarest, 1988), que sirvió como mecanismos de control económico, político y social de las poblaciones conquistadas especialmente por el estado inca.

Finalmente tenemos la tripartición vertical de Hananpacha, Kaypacha y Ucupacha, conceptos muy arraigados en la cosmovisión andina, debido a que articula tres espacios, que, en este caso, la huanca es el eje controlador que se proyecta en la vida cotidiana. La esencia fundamental radica en que esta huanca por su naturaleza polivalente se comporta de distintas maneras (Duviols, 1979; Farfan 2012). Al estar plantado en tierra se conecta con la mamapacha (Ucupacha) y el mundo en que vivimos (Kaypacha), este hecho, lo convierte en un símbolo fertilizador, dado que la huanca es un ancestro litificado y puede controlar el agua que discurre por los canales. Dentro de esta estructura, tanto la serpiente como el cóndor actúan como intermediarios entre el ucupacha y el kaypacha, es decir entre el mundo de los muertos y el mundo de los vivos o entre el hanapacha y el kaypacha para el caso del cóndor. Sin embargo, esta huanca está relacionado al pueblo o marca, puesto que cuando actúa de ancestro se evoca a un tiempo de fundación, de origen. Esto es factible identificar en los discursos míticos relacionados al agua, en el llamado fiesta del agua y arqueológicamente es en las tumbas o espacios sepulcrales de la pareja mítica que hallamos en Cantamarca, Aynas, Huishco y Tauripunku (Farfan, 2000, 2008, 2011). Estos entierros son muy recurrentes en áreas expresamente remarcadas en la población como espacios sepulcrales dedicados a estos ancestros. El mismo fenómeno es factible identificar en los sepulcros de los machays o cuevas donde se enterraron los personajes más importantes con su parentela acompañada y quizá en rituales y ofrendas de sacrificios humanos. 


\section{ESPACIO SACRALIZADO Y PODER}

Los espacios sacralizados permiten introducir al hombre hacia una dimensión sin tiempo, es el lugar donde rito y el mito se consagran, donde todo puede ser posible, es el lugar donde los mitos adquieren significación y legitiman el acto ya sea propiciatorio o evocativo. Arqueológicamente los espacios sacralizados forman parte de los asentamientos y su entorno. Los lugares de enterramiento por ejemplo definen un espacio sacralizado, pero cuando los entierros forman parte del espacio doméstico, ya sea patio o recinto, entonces el concepto de espacio sacralizado adquiere otra dimensión, es decir, tanto el espacio doméstico como el espacio sepulcral conforman una unidad sagrada dentro del pensamiento andino. Así, los entierros que hallamos tanto en Cantamarca, Aynas, Huishco, Tauripunku en el alto Chillón son un ejemplo de esta percepción debido a que en estos lugares las excavaciones arqueológicas han demostrado que hay un patrón de enterramiento en áreas habitacionales.

En Cantamarca, los entierros se presentan en cámaras subterráneas en pares. En Aynas y Huishco en cambio son en cámaras también en patios y recintos, pero son entierros múltiples, mientras que en Tauripunku, también están en el área habitacional pero alineados. Como podemos notar el patrón son entierros en espacios habitacionales, pero pueden variar las características de los entierros de unitarios a múltiples, de cámaras a cuevas. Entonces, el problema es saber ¿quiénes se entierran en las áreas domésticas, serán los ancestros fundadores?, ¿héroes guerreros? o simplemente el ancestro del linaje familiar. Pero desde ya el espacio urbano era sacralizado en el momento en que deciden acondicionar a sus muertos cerca de su vivienda.

Otros lugares son los cerros y montañas donde se practicó el rito de la capacocha como el caso de Cahuara en el valle alto de Canta a 4050m.s.n.m., donde aún se conserva su sacralidad en llevar ofrendas en ritos secretos cada principio de año a cargo de la Comunidad Campesina de Viscas. Hernández Príncipe en su visita a Ocros relata los entierros en pozos profundos tal como se hacían en el Cusco con las acllas en las fiestas llamadas capacocha.

Así en Ocros había sido escogida Tanta Carhua una niña hija de Caque Poma y llevado a este sacrificio por mandato del inca. El propósito decía que: dicha capacocha era para la guarda y custodia de toda la provincia (Zuidema, 1978; Duviols, 1986). Pero la que ha concitado mayor interés son los llamados montañas sagradas en nevados por contener en sus entrañas ofrendas de capacocha. Constanza Ceruti ha desarrollado un estudio sobre las cumbres sagradas y como epilogo a este estudio nos dice:

“... que las montañas han sido reconocidas como lugares sagrados; escalera al cielo y morada de los dioses, flechas que apuntan a lo eterno, son algunas de las metáforas 
con las cuales se ha querido arrojar luz sobre la cualidad que poseen las montañas para invitar a la meditación y a la contemplación...", (Constanza Ceruti, 1999:179).

Sin duda, la arqueología de alta montaña ha demostrado una especial dedicación de parte de las sociedades prehispánicas, con los grandes hallazgos de entierros sacrificados en honor a los dioses de los cerros que reforzaría más la sacralización del paisaje, en nuestro caso, ¿el nevado de Pariacaca fue un destino de sacrificios y ofrendas? Duviols publica un documento denominado carta annua de la Provincia del Perú de la Compañía de Jesús firmada por el provincial Juan Sebastián en 30 de abril de 1612. En este documento se relata la destrucción y "muerte "de Pariacaca, un ídolo que moraba en un boquerón al final de Las escaleras en la cordillera del Pariacaca y dic:

\begin{abstract}
“...llegamos entre las diez y las once del día al pie del cerro o peñasco el qual es muy grande y de notable altura, pero muy acomodado para poder subir a lo más alto del porque tenía unas gradas hechas de piedra por donde subían los yndios a hazer su adoración y sacrificio en su fiesta y nosotros subimos por aquellas gradas no con mucha dificultad. A lo último de la escalera estatua una boca que era el lugar donde echaban el tecgte chicha y sangre de animales...". (Duviols, 1997:645).
\end{abstract}

Más adelante dice:

\begin{abstract}
Mandole el doctor tapar a piedra y lodo y en la parte que mira al camino real de donde se descubre muy bien poner una cruz en medio y otra muy grande y vistosa en lo alto y cumbre del peñasco (Duviols, 1997:645).
\end{abstract}

Luego el documento enfatiza la algarabía de la gente que lo acompañaba porque ya Pariacaca había muerto al ser sepultado con piedras y lodo. Lo importante de este relato es el cuestionamiento de que ¿Pariacaca estaba materializado en un ídolo? De manera que ¿moraba en una cueva o peñasco al final de las escaleras? En las exploraciones que hicimos en varias oportunidades reeditamos esta trayectoria conforme al relato, pero nunca hemos encontrado ningún indicio de este boquerón. El lugar al que se refiere el relato es conocido como Escalerayoc o también "Las Escaleras" cerca del abrigo rocoso de Cuchimachay, en la cordillera del Pariacaca.

Pero no solo este boquerón con el ídolo de Pariacaca sacralizaba este lugar sino también estaba precedido por pinturas rupestres que datan desde el periodo lítico, lo cual sustenta que el paisaje de Pariacaca ya era sagrada (Farfan, 2008).

Los paisajes sacralizados fueron manipulados con el fin de cohesionar a la sociedad, legitimar los derechos de propiedad y demarcar sus identidades de linaje y ancestralidad.

Estos causales primigenios fueron utilizados por las elites gobernantes para administrar poder y control sobre la sociedad y de este modo tener el control también sobre la economía y el territorio, para lo cual, se estructuraron aparatos de control estatal como lo hicieron los incas. 
A manera de conclusión podemos decir que la sacralización del paisaje es un proceso a partir de su apropiación, primero con fines de subsistencia, luego con fines de elección del habitad para su asentamiento, donde este paisaje forma parte del entorno y su vida cotidiana, al mismo tiempo genera referentes fijos y movibles con las que se construye la esfera de su cosmovisión en base a una percepción simbólica de la realidad. Como parte de la legitimación de estos referentes simbólicos se estructuraron historias, leyendas y mitos de carácter evocativo y propiciatorio. Pero luego ya cuando las sociedades se complejizan estos referentes simbólicos y sagrados y la sacralización son utilizados como mecanismo de control por parte de elites estatales para legitimar su poder.

\section{AGRADECIMIENTOS}

En primera instancia queremos agradecer a todos nuestros alumnos de la especialidad de arqueología del UNFV y los alumnos de la UNMSM Manuel Perales Munguía, Anderson Chamorro, Luis Alberto Sánchez Palomino, Jhonny Apcho y otros más en los inicios de esta tarea con quienes hemos recorrido casi todas las cuencas de los andes centrales y las cordilleras de la vertiente del pacifico. Del mismo modo a todos los miembros de la Comunidad Campesina de Huaros, San José de Tauripunku de la cuenca del Chillón y a las Comunidades campesinas de Huarochirí, y en forma especial al Alcalde de este distrito Sr. Guillermo Cuellar al Dr. Edwin Santos Hurtado y Emilio Torres Mosquito del distrito de Huaros, incansables huarocinos que nos apoyó desinteresadamente para nuestras investigaciones. Así mismo a mis alumnos que nos acompañaron a Huarochirí cuyos frutos ya son tesis de Licenciatura de Yadelith Noel Veramendi, Humberto Paitamala Sáenz, y en proceso Lea Lorena Rojas y Javier Kam Loy a quienes también van mis agradecimientos. Sin todos ellos no hubiese podido desarrollar este trabajo. 


\section{REFERENCIAS}

Bate, Luis F.

1998 El Proceso de Investigación en Arqueología. Ed. Critica Grijalbo Mondadori, S.A. Barcelona, España.

Benfer, Robert y Ludeña, Hugo

2004 Proyecto de investigación arqueológica pozos de prueba en los sitios arqueológicos de buena vista y la quipa - 1st etapa. Informe Preliminar.

Binford, Lewis

1972 An Archaeological Pespective. Seminar Press New York and London

1988 En busca del pasado. Editorial Crítica, Barcelona

Bustamante, Díaz G.

2008 Posible Ubicuidad Espacio-temporal de la triada Paraidolia-Apofenia-Hierofania, como probable origen de la sacralización de algunos elementos del paisaje. Rupestreweb, 1 de julio de 2008.

Conrad G. Y Demarest A

1988 Religión e Imperio. Alianza Editorial S.A. Madrid, España.

Constanza, Ceruti M.

1999 Cumbres Sagradas del Noreste Argentino. Avances en arqueología de alta montaña y etno-arqueología de santuarios de altura andinos. Editorial Universitaria de Buenos Aires, Argentina.

Clarke, David

1984 Arqueología Analítica. Segunda Edición, Editorial Bellaterra, S.A. Barcelona

Criado, L. Felipe

1999 Del Terreno al Espacio: Planteamientos y Perspectivas para la Arqueología del Paisaje. CAPA 6, Criterios y Convenciones en Arqueología del Paisaje. Universidad de Santiago de Compostela. Galicia, España.

Duviols, Pierre

1979 "Un simbolismo de la ocupación, emplazamiento y explotación del espacio. El monolito huanca y su función en los andes prehispánicos”. En L’HOMME, Revue Francaise d'antropologie. Tome XIX, Avril-Juin 1979. Número 2. Traducción de Lilia Lázaro de Paredes, 1987.

1997 ¿Dónde estaba el santuario de Pariacaca? En Arqueología, Antropología e Historia en los Andes. Homenaje a María Rostworowski. IEP.

1986 Cultura Andina y Represión: Procesos y visitas de idolatrías y hechicerías, Cajatambo, siglo XVII. Centro de Estudios Rurales Andinos Bartolomé de las Casas.

Eliade, Mercia

1973 Lo sagrado y lo profano. Guadarrama, Madrid, España, p. 25-28

Espinoza, Waldemar

1977 Los cuatro suyos del Cusco, siglos XV y XVI. En Boletín del IFEA, Vol. VI, N³,4, pp. 109-122. 
Farfan Lobaton, Carlos

2000 La Ocupación Inca en Cantamarca. En: Arqueología y Sociedad N 3, pp. 173 - 198. Museo de Antropología y Arqueología UNMSM.

2002 Simbolismo en torno al agua en la comunidad de Huaros, Canta. En Boletín del Instituto Francés de estudios Andinos, $\mathrm{N}^{\circ} 31$ (1), 115 - 142., Lima

2002a La Bipartición del Espacio y las Plazas Sagradas en los Asentamientos Prehispánicos de la Cuenca del Chillón. En: Supay, Revista de Humanidades, Lima, Año 4, №3.

2007 El culto al agua y la danza de los quivios en la Comunidad de Huaros, Canta. En Runamanta. Revista de Antropología, N²-3, Segunda Época. Universidad Nacional Federico Villarreal.

2008 Poder simbólico y poder político del estado inca en la cordillera del Pariacaca. En: Arqueología en el Perú. Nuevos aportes para el estudio de las sociedades andinas prehispánicas. Ruben Romero y Trine Pavel, Editores.

2012 El Huanca y su dimensión simbólica en la arqueología de la sierra central. En Arqueologia y Sociedad N²4, Museo de Arqueología y Antropología de la UNMSM, Lima, p.392-402.

Flannery Kent.

1967 Introducción a la Arqueología: Historia Cultural vs. Proceso Cultural. Un debate de la arqueología americana, 1967. Re-impreso en: Contemporany Archaeology. Edit. Por Mark Leone. Southern Illinois Press, 1972.

Gandara, Manuel

1980 La vieja "Nueva Arqueología" Primera Parte. Boletín de Antropología Americana №2. Instituto Panamericano de Geografía e Historia, México, D.C. p.7-45.

Gonzales, José Luis

1989 El Huanca y la Cruz: Creatividad y autonomía en la religión popular. Ediciones IDEA y TAREA, Lima.

Guamán Poma de Ayala, Felipe

1936 Nueva Corónica y buen Gobierno. (Codex péruvien illustré). Paris, Institut D’ethnologie. Université de Paris.

Guffroy, Jean

1999 El Arte Rupestre en el Antiguo Perú. Ed. Instituto Francés de estudios Andinos, Institut de Recherche pour le Developement, IRD.

Hempel, Karl, G.

1979 La explicación Científica. Paidos Básica, Barcelona

Hyslop, John

1992 Qhapaqñan. El Sistema vial Inkaico. Instituto Andino de Estudios Arqueológicos. Petróleos del Perú.

Hodder, Ian 
1994 Interpretación en Arqueología. Corrientes Actuales. CRITICA, Grupo Grijalbo-Mondadori, Barcelona.

Johnson, Matthew

2000 Teoría Arqueológica: una introducción. Ed. Ariel Historia, Barcelona

Kuhun, S. Thomas

1992 La estructura de las revoluciones científicas. Fondo de Cultura Económica, México, edición castellana; primera edición en inglés, 1962, University of Chicago press).

Murra, Jhon

2002 El Mundo Andino: población, medio ambiente y economía. Pontificia Universidad Catolica del Peru. Fondo Editorial. IEP Instituto de estudios Andinos, Lima.

Paredes, Ponciano

2003 “Ocros: 500 años después: Acerca de los linajes de Caque Poma y Tanta Carhua.” En Boletín de la Sociedad geográfica de Lima, Año 112, Vol. №116.

Popper, Karl R.

1972 La lógica de la investigación científica. Editorial Tecnos S. A. Madrid, España.

Regalado, Liliana

1996 Espacio andino, espacio sagrado: visión ceremonial del territorio en el periodo incaico. En Revista Complutense de Historia de América, 22. UCM.

Rostworowski de Diez Canseco, María

1986 Estructuras Andinas del Poder: ideología religiosa y política. IEP, Segunda edición.

Santos, Hurtado E.

2003 Análisis de los mitos de los "Comuneros de Huaros" desde la Teoría del Inconsciente Colectivo. Tesis para optar el grado de Doctor en Medicina, Universidad Peruana "Cayetano Heredia".

Taylor, Gerald

1987 Ritos y Tradiciones de Huarochirí del siglo XVII. Instituto de estudios Andinos. Instituto

Francés de Estudios Andinos.

Urbano, Henrique

1987 Thunupa, Taguapaca, Cachi: Introducción a un espacio simbólico andino. En Revista Andina, Año 6, N¹, Centro Bartolomé de las Casas, Cusco, Perú.

Urton, Gary

2006 En el cruce de rumbos de la tierra y el cielo. Bartolomé de las Casas, Cusco.

Zuidema, Tom.

1966 "Calendario Inca”. En Actas del XXXVI Congreso de Americanistas, Separata del Vol. 2, p.2530.

1978 "Shaft tombs and the Inca Empire". En Journal of the Steward Anthropological Society, vol. 9 $\mathrm{N}^{\circ} 1-2$, p. 133-178. 
Zuidema, Tom

1995 El sistema de ceques del Cuzco: la organización social de la capital de los Incas" Pontificia Universidad Católica del Perú, Fondo Editorial 1995

Zuidema, T. \& Poole, D

1982 Los Límites de los cuatro suyos incaicos en el Cusco. En Boletín del Instituto Francés de Estudios Andinos. Año XI, N 1,2. Lima, Perú.

Villar Córdova. Pedro

1933 EL mito "Wa-Kon y los Willka" referente al culto indígena de la cordillera de La Viuda. Revista del Museo Nacional, Tomo II, N².

1935 Las culturas prehispánicas del departamento de Lima. Municipalidad de Lima, Lima-Perú. Watson, P. - Leblanc, S. - Redman, CH.

1974 El Método Científico en Arqueología. Alianza Universidad, Madrid España 